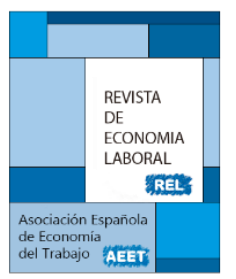

\title{
DESIGUALDAD LABORAL POR GÉNERO EN MÉXICO: ANÁLISIS DE LAS ÁREAS URBANAS
}

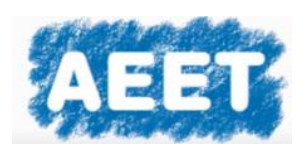

\author{
Albany Aguilera Fernández y David Castro Lugo ${ }^{1}$ \\ Universidad Autónoma de Coahuila \\ Recibido Diciembre 2017; Aceptado Enero 2018
}

\section{Resumen}

El artículo tiene como objetivo determinar la desigualdad laboral por género en las áreas urbanas de México, para los años 2005 y 2016. Con información de la Encuesta Nacional de Ocupación y Empleo (ENOE), se construye un indice de desigualdad laboral que considera variables relacionadas con la participación laboral, ocupación, desempleo, remuneraciones, informalidad, segregación sectorial y condiciones laborales. Los principales resultados muestran heterogeneidad entre los componentes del indice y, sugieren que, aun cuando se ha avanzado hacia la igualdad laboral por género, en algunas ciudades la desigualdad entre hombres y mujeres se ha mantenido persistente.

Palabras claves: Desigualdad laboral por género, mercado laboral, áreas urbanas, México. Clasificación JEL: J16, J21, J24, J70

\footnotetext{
1 Los autores agradecen el apoyo recibido por PRODEP para la realización de este documento.
}

(C) Revista de Economía Laboral 


\begin{abstract}
The article aims to determine gender labor inequality in urban areas of Mexico, for the years 2005 and 2016. With information from the National Survey of Occupation and Employment (ENOE), an inequality index is constructed that considers variables related to labor participation, occupations, unemployment, remunerations, informality, sectoral segregation and working conditions. The main results show heterogeneity among the index components and suggest that, although progress has been made towards labor equality by gender, in some cities inequality between men and women has remained persistent.
\end{abstract}

Key Words: Gender labor inequality, labor market, urban areas, Mexico.

Classification JEL: J16, J21, J24, J70 


\section{Introducción}

Históricamente, en México y en el mundo se ha presentado una división sexual del trabajo que, consigna en mayor medida a las mujeres en actividades del hogar y a los hombres al trabajo remunerado. Si bien esos patrones han evolucionado en los últimos 30 años, las diferencias entre mujeres y hombres respecto a las tareas que desempeñan para el mercado laboral y las de tipo doméstico determinan algunas de las desigualdades de género más significativas.

El problema de la desigualdad entre hombres y mujeres ha sido persistente en los mercados laborales mundiales en lo referente a las oportunidades, al trato y a los resultados (OIT, 2016). De ahí que, como política universal, en el año 2015 los Estados miembros de las Naciones Unidas adoptaron la agenda 2030 para el Desarrollo Sostenible, que refuerza la importancia de lograr la igualdad de género e impulsar acciones que apuesten al crecimiento inclusivo, con pleno empleo productivo y trabajo decente para mujeres y hombres.

En este contexto y pese a que el Estado mexicano ha promovido iniciativas con objeto de integrar el principio de equidad de género en las políticas públicas y acciones gubernamentales, aún se requieren esfuerzos para avanzar en el logro de la igualdad sustantiva entre ambos sexos. Esto se evidencia en el Informe Global de la Brecha de Género 2016 elaborado por el Foro Económico Mundial (WEF por sus siglas en inglés), que situó a México en el puesto 66 en la lista de 144 países por obtener una brecha de género del 70 por ciento, y en el lugar 128 con relación a la desigualdad en los salarios que reciben hombres y mujeres por el mismo trabajo. El reporte destaca una disminución en la participación y las oportunidades de desarrollo económico de las mujeres en el país, además de mayor cantidad de trabajo no remunerado en comparación con los hombres. Aunado a lo anterior, la tendencia observada en el mercado laboral refleja un deterioro de la calidad del empleo, con cerca de 29.5 millones de mexicanos laborando en el sector informal y una tasa de desocupación de 4.0 por ciento en 2016 , al tiempo que se ha presentado una reducción de los salarios reales desde 2014.

Lo comentado hasta ahora, denota la necesidad de adoptar medidas que coadyuven a incrementar la participación equitativa en la fuerza laboral y el acceso al empleo formal, con miras a lograr una sociedad incluyente, mejorar la situación social y económica de la población, obtener mayores niveles de producción y reducir la desigualdad de ingresos (OIT, 2016); no obstante, para emprender acciones afectivas es necesario conocer la realidad de los mercados de trabajo, tomando en 
cuenta que México es un país heterogéneo, espacial y sectorialmente, donde el modelo de apertura comercial no parece haber atenuado tales diferencias.

Dado lo anterior, la investigación tiene como objetivo determinar la desigualdad laboral por género en las áreas urbanas de México para los años 2005 y 2016, con el fin de hacer un comparativo que muestre la evolución y situación actual. Con datos procedentes de la Encuesta Nacional de Ocupación y Empleo (ENOE) y la aplicación de técnicas estadísticas, se propone un índice general de desigualdad laboral que integra componentes específicos que permiten valorar los factores que propician la disparidad entre hombres y mujeres considerando diferentes dimensiones.

Los principales hallazgos expresan comportamientos diferenciados en el mercado de trabajo de las áreas urbanas de México ${ }^{2}$. Mientras algunas ciudades han avanzado hacia una mayor equidad laboral (Tijuana, Tampico, Cancún, Chihuahua, La Paz, Zacatecas, Acapulco, Culiacán, Veracruz, Puebla, Durango, Oaxaca, Hermosillo, Campeche, Morelia y Pachuca), hay otras en dónde las disparidades se han acentuado (Mérida, Aguascalientes, León, Tepic, Tuxtla Gutiérrez, Monterrey, Guadalajara y Querétaro). Lo que habla de la existencia de un comportamiento heterogéneo en materia de desigualdad laboral por género al interior del país $\mathrm{y}$, por lo tanto, sugiere la necesidad de implementar políticas focalizadas hacia las áreas vulnerables.

El resto del documento se encuentra organizado como sigue. Se inicia exhibiendo la evidencia empírica que ha abordado el análisis del mercado laboral y su división por sexo. Enseguida se mencionan las principales transformaciones ocurridas en la economía mexicana y su mercado de trabajo. En el apartado metodológico se describe la construcción del índice de desigualdad laboral, los componentes que lo integran, así como la base de datos utilizada. La quinta sección aborda los principales hallazgos obtenidos, y finaliza con las conclusiones.

\footnotetext{
2 Para la identificación geográfica en el territorio nacional mexicano véase el mapa posterior.
} 


\section{Desigualdad laboral entre hombres y mujeres: importancia de estudio y evidencia}

La desigualdad ${ }^{3}$ es una característica histórica y estructural que ha distinguido a las sociedades a nivel mundial, manifestada de manera más elocuente en la distribución del ingreso, lo que ha derivado en otras disparidades relacionadas con el género, la educación y el mercado de trabajo (CEPAL, 2017). Desde los ámbitos económico y social, la desigualdad por género se ha posicionado como tema clave entre los académicos y los hacedores de política pública (Arceo y Campos, 2014). Prueba de ello es que, en el año 2015 los Estados miembros de las Naciones Unidas adoptaron el programa "Transformar nuestro mundo: la Agenda 2030 para el Desarrollo Sostenible”, el cual estableció como eje central el compromiso por cumplir los Objetivos de Desarrollo Sustentable (ODS).

La agenda 2030 para el Desarrollo Sostenible intenta afrontar las persistentes disparidades entre hombres y mujeres en los mercados laborales mundiales. De forma específica se refuerza la importancia de lograr la igualdad de género en el Objetivo 5; mientras que el reto planteado por el Objetivo 8 consiste en impulsar acciones que apuesten al crecimiento inclusivo y sostenible, con pleno empleo productivo y trabajo decente para mujeres y hombres, así como la paridad de remuneraciones por trabajo de igual valor (OIT, 2016).

En este contexto, el Programa de las Naciones Unidas para el Desarrollo (PNUD) propuso de manera oficial, un índice de desigualdad de género (IDG) para México. El cual refleja la desventaja que pueden experimentar las mujeres en el desarrollo humano con respecto a los hombres, debido a la desigualdad en tres aspectos: salud reproductiva, empoderamiento y mercado laboral. En particular, la dimensión de mercado laboral reveló que para el periodo 2008-2012, 43 por ciento de las mujeres mayores de 14 años formaba parte de la población económicamente activa (PEA), cifra significativamente inferior a la de los hombres (78 por ciento). De acuerdo con el PNUD, en el año 2012 la desigualdad de género fue menor en México (valor de 0.393) que la experimentada en América Latina y el Caribe (0.419); no obstante, resultó superior a la exhibida en Europa y Asia Central. Pese a que el estudio corrobora un avance de la desigualdad de género, concluye que hay entidades en las que aún es persistente (PNUD, 2016).

3 A lo largo de este documento se utilizarán como sinónimos los términos: desigualdad, disparidad e inequidad. 
Dado lo anterior, para formular políticas o programas que permitan avanzar hacia la equidad, es fundamental entender los determinantes de la desigualdad por género en los mercados laborales, su magnitud e interrelaciones (CEPAL, 2014). Como se ha discutido en la literatura especializada, esta se sustenta en una división sexual del trabajo que atribuye a las mujeres los quehaceres domésticos y el cuidado de los hijos sin recibir pago, lo que desencadena una reducción del tiempo y oportunidades para participar en el trabajo remunerado y, por ende, acceder a prestaciones laborales y protección social (Bonet, 2004; CEPAL, 2013; OCDE, 2017). Lo anterior posiciona a la población femenina en una condición desfavorable en contraste con los hombres, en aspectos relacionados a la desigual asignación de trabajo no remunerado, diferencial salarial, elevadas tasas de paro e informalidad, subempleo con contratos a tiempo parcial, desprotección social y económica, discriminación salarial y segregación ocupacional (Cervantes 2015; CEPAL, 2017).

Investigaciones sobre la inserción de las mujeres y hombres en los mercados de trabajo (Whitehouse, 1992; Gonas, 2000; Bonet, 2004; England, 2005; Rendón y Maldonado, 2005; García, 2008; Riobóo y Martín, 2010; CEPAL, 2013 y 2017; OCDE, 2017) corroboran lo comentado previamente. Es decir, proporcionan evidencia de las desigualdades de género en distintos parámetros del mercado laboral (participación en la fuerza de trabajo, empleo, paro, nivel de ingresos, acceso a ocupaciones, entre otros indicadores). Cabe aclarar que, los resultados divergen entre los países e incluso entre las mujeres de una misma nación si se considera el grado educativo, el número de dependientes menores de edad presentes en el hogar, la raza o etnia (CEPAL, 2017). De ahí que, resulta pertinente continuar con un análisis sobre el contexto económico de México y el comportamiento que han exhibido los principales parámetros del mercado de trabajo.

\section{Contexto económico de México y el mercado de trabajo}

La economía mexicana ha registrado un crecimiento de su producto interno bruto (PIB) relativamente bajo, ya que en los últimos 20 años alcanzó un promedio de 2.6 por ciento anual de acuerdo con información de la Secretaría de Economía, lo que ha resultado insuficiente para absorber el crecimiento de la oferta de trabajo. 
Adicionalmente, la crisis financiera global que se agudizó en Estados Unidos en 2008 y 2009 vulneró el sector externo y el empleo en México, a causa de la fuerte dependencia económica del país hacia la nación vecina del norte ${ }^{4}$. Hecho que se corrobora con el descenso, en 2009, del 24 y 23 por ciento de las exportaciones e importaciones respectivamente. Asimismo, las principales variables macroeconómicas tuvieron comportamientos desfavorables: la inflación alcanzó 6.5 por ciento; el PIB creció a una tasa del 1.2 por ciento en 2008 y disminuyó 6 por ciento en 2009. En 2010 se percibió una recuperación económica, sin embargo, en los últimos años, la economía mexicana se ha caracterizado por el lento crecimiento asociado a una mayor volatilidad, reflejo de las condiciones imperantes en la economía mundial.

A pesar de que la apertura hacia los mercados mundiales que mantiene México estimuló el comercio exterior, atrajo flujos de inversión extranjera directa (IED) y alentó el establecimiento de nuevas empresas (Blecker, 2010), la economía siguió caracterizándose por altos índices de informalidad, mano de obra poco calificada, productividad escasa y tecnologías obsoletas (Cervantes y Acharya, 2013; OCDE, 2015b). Dado lo cual, el gobierno mexicano emprendió una serie de reformas estructurales ${ }^{5}$, tendientes a hacer más incluyente el crecimiento, reducir la desigualdad del ingreso, impulsar el trabajo decente y equitativo, así como desarrollar la calidad educativa y la competitividad (OCDE, 2012; Rocha, 2013; IMCO, 2014).

Dentro de estas iniciativas de ley, se inició con la reforma laboral en 2012, en busca de brindar mayor certidumbre a los trabajadores y empresas y, a su vez, mejorar las condiciones para la creación de empleos formales. Al respecto, analistas señalan falta de profundidad en los temas de transparencia sindical aunado a la existencia de brechas de implementación local (Molano, 2014); por su parte, la Organización para la Cooperación y el Desarrollo Económicos (OCDE) advierte que se requieren iniciativas adicionales para expandir la formalidad, especialmente en mujeres y jóvenes (OCDE, 2015a).

Dadas las preocupaciones sobre la competitividad en la economía global y el mercado laboral, en ese mismo año 2012 se hizo obligatoria la educación media superior y, de forma complementaria, se han promovido estrategias para lograr aumentar los índices de acceso, permanencia y

\footnotetext{
${ }^{4}$ Estados Unidos de América es el principal socio comercial de México; más del 65 por ciento del comercio exterior es con dicha nación.

${ }^{5}$ Las reformas aprobadas se encuentran disponibles en:

http://www.diputados.gob.mx/LeyesBiblio/index.htm
} 
conclusión de estudios medio superior y superior. Aunque la matricula en el nivel superior se ha incrementado considerablemente, sólo el 16 por ciento de los adultos mexicanos alcanzaron estudios de educación superior en 2015, el porcentaje más bajo entre los países de la OCDE (promedio de 36\%). Aun así, más del 50 por ciento de la población que culmina los estudios de educación superior son del sexo femenino; mientas en los programas de doctorado o equivalente, la presencia de mujeres es inferior (Salgado y Miranda, 2007; Hanushek y Wößmann, 2007; OCDE 2016).

Pese a lo anterior, son las mujeres quienes se encuentran en desventaja en el mercado laboral. Con relación al salario, que constituye la principal fuente de ingresos de los hogares no solo en México sino también a nivel mundial ${ }^{6}$ (OIT, 2017), las trabajadoras que cuentan con instrucción superior perciben una remuneración equivalente al 69 por ciento de lo que ganan los hombres con educación similar; esta brecha salarial por género se posiciona como la tercera más alta entre los países de la OCDE (promedio de 73\% en el año 2015) (OCDE, 2016).

Lo anterior, establece la importancia de contrarrestar la desigualdad salarial, problema que se han presentado con mayor persistencia en los mercados de trabajo mundiales. Tanto la desigualdad salarial entre hombres y mujeres, como la discriminación salarial por razón de sexo, se han convertido en temas recurrentes en la literatura relacionada con las diferencias de género (Brown et al., 1999; Pagán y Sánchez, 2000; Castro y Huesca, 2007; Calonico y Nopo, 2009; Aguayo et al., 2010; Popli, 2013; Arceo y Campos, 2014; Rodríguez y Castro, 2014a y b; Castro et al., 2015; Rodríguez y Castro, 2017; Rodríguez, 2018). En síntesis, los trabajos han analizado la existencia de estos fenómenos a nivel nacional, regional y local desagregados por grupos de trabajadores y sectores económicos, los cuantifican, explican sus causas y/o proponen medidas de actuación política que contribuyan a detectarlos y erradicarlos.

Adicionalmente, un reto importante en materia de política gubernamental lo constituye el nivel de desempleo que, en conjunto con los bajos ingresos y la desigualdad salarial, ayudan a justificar el flujo migratorio de la mano de obra hacia los Estados Unidos de América (Ruiz y Ordaz, 2011; Figueroa et al., 2012). A escala nacional, la tendencia de la tasa de desempleo se ha ubicado entre 3 y 5 por ciento, con excepción de los periodos de crisis económica (1994-1995 y 2008-2009) que alcanzó

\footnotetext{
${ }^{6}$ En las economías desarrolladas los salarios constituyen aproximadamente el 70 y 80 por ciento del total de la renta familiar, mientras que en las economías emergentes y en desarrollo oscila entre un 50 y 60 por ciento.
} 
niveles superiores al 5 por ciento. Desde la perspectiva de género las mujeres conservan tasas más elevadas (Cervantes, 2015); incluso, en 2011 la tasa masculina fue 3.8 puntos porcentuales inferior a la femenina (mujeres 8.2 y hombres $4.4 \%$ ).

En un comparativo internacional, México se posicionó como uno de los países miembros de la OCDE con menores tasas de desempleo en 20147. No obstante, es importante mencionar que una baja tasa de desocupación puede derivarse de las siguientes razones: migración internacional, cambios en la edad mínima para trabajar (de 12 a 14 años y de 14 a 15 años), laxa definición de ocupados, así como la inexistencia de seguro de desempleo (Ruíz y Ordaz, 2011).

De lo comentado previamente, se puede resumir un bajo dinamismo de la economía mexicana y la vigencia de una reducida tasa de desempleo en el mercado laboral, que han coexistido con un alto y persistente empleo informal (Negrete, 2012). En la mayoría de los países en desarrollo, el empleo informal es un componente de la mano de obra mayor que el formal, lo que representa un importante obstáculo para el desarrollo incluyente (Martínez et al., 2016). En México, un porcentaje considerable de empleos creados posterior a la crisis financiera global de 2008-2009 fueron en el sector informal, ya que, en el año 2014 llegaron a representar el 58.8 por ciento de la ocupación total.

De acuerdo con la OCDE (OCDE, 2014) y la Organización Internacional del Trabajo (OIT, 2014), el principal desafío que enfrenta el gobierno mexicano implica adoptar estrategias que permitan generar puestos de trabajo de calidad y disminuir los incentivos para permanecer en la informalidad, debido a que esta tiene un efecto adverso sobre las competencias, el capital humano, la eficiencia y la equidad de la economía en su conjunto.

En resumen, a nivel internacional existe un reconocimiento político con respecto a la importancia del análisis del mercado laboral. En particular, se aboga por la generación de empleos productivos, oportunidades de trabajo decente, mejoras de los niveles salariales, así como la igualdad de género en las condiciones laborales como fin y medio para alcanzar el bienestar para la población y la consolidación de sociedades más justas (CEPAL, 2014; OIT, 2016; OCDE, 2017). Al respecto, aunque se han logrado avances en la incorporación de la población femenina a la fuerza de trabajo, la desigualdad entre hombres y mujeres en el mercado laboral continúa persistente. Por lo que, en la siguiente sección se presenta la metodología que permitirá cuantificar e

\footnotetext{
${ }^{7}$ Para mayor detalle consultar OECD Employment Outlook 2014.
} 
identificar los parámetros que inciden sobre el nivel de desigualdad laboral por género en las áreas urbanas de México.

\section{Metodología y fuente de información}

\subsection{Metodología}

Con la intención de aportar una alternativa que evalúe el grado de equidad de género en el mercado laboral de México, se ha optado por elaborar un índice de desigualdad laboral (IDL) integrado por siete componentes. Para ello se han considerado elementos complementarios que impactan directamente sobre la participación en el mercado de trabajo, el personal ocupado, la población juvenil, el nivel de calificación, las remuneraciones y las condiciones laborales.

Antes de presentar cada uno de los componentes que integran el IDL, reconocemos que el indicador propuesto es inevitablemente imperfecto, pero representa variables sobre las cuales existe información disponible y homogénea $\mathrm{y}$, en conjunto, puede explicar de manera integral la estructura del mercado de trabajo en las áreas urbanas mexicanas. Es relevante señalar que, el IDL explora sobre la magnitud y evolución de la desigualdad laboral por género y no sobre la calidad del mercado laboral; así, es posible que se presente una reducción de la brecha laboral por género, aunque esta pueda estar acompañada de un deterioro en las condiciones del mercado laboral.

A continuación, se precisan las características de las variables que integran cada uno de los siete componentes del IDL:

I. Desigualdad en participación laboral (DPL). Determina las diferencias en las oportunidades que tienen las mujeres y hombres para acceder al trabajo remunerado, según su nivel de instrucción.

a) Tasa de participación en la fuerza de trabajo por sexo: proporción que representa PEA respecto al total de la población mayor de 15 años.

b) Tasa de participación calificados: considera a los individuos que tienen 15 o más años de escolaridad.

c) Tasa de participación semi-calificados: considera a los individuos que tienen entre 10 y 14 años de escolaridad.

d) Tasa de participación no calificados: considera a los individuos que tienen entre 0 y 9 años de escolaridad. 
II. Desigualdad en ocupación (DO). Refleja las diferencias entre la categoría ocupacional y las jornadas laborales de hombres y mujeres que se encuentran empleados.

a) Tasa de ocupación: población que participó en la generación de algún bien económico o en la prestación de un servicio, respecto al total de la población mayor de 15 años.

b) Tasa de trabajo asalariado: población ocupada que percibe de la unidad económica para la que trabaja un sueldo, salario o jornal por las actividades realizadas, en relación con la población ocupada total.

c) Tasa de empleadores: trabajadores independientes que utilizan de manera regular al menos un trabajador remunerado en la conducción de su negocio, en relación con la población ocupada total.

d) Tasa de trabajadores por cuenta propia: personas ocupadas que desempeñan su oficio o profesión, y no tienen trabajadores a sueldo o bajo alguna otra forma de retribución monetaria.

e) Tasa de ocupación con jornadas de tiempo completo: hombres y mujeres que trabajan de 35 a 48 horas a la semana, correspondiente a la jornada legal máxima de trabajo en México.

f) Tasa de ocupación con jornadas de tiempo parcial: hombres y mujeres que trabajan de 15 a 35 horas a la semana.

III. Desigualdad en paro (DP). Representa la subutilización de la oferta de mano de obra en la economía y, por su volatilidad, debe estudiarse junto con las medidas de la oferta y demanda de trabajadores.

a) Tasas de paro: población desocupada con relación a la PEA.

b) Tasas de paro jóvenes: población desocupada menor de 25 años de edad.

c) Tasas de paro adultos: población desocupada mayor de 25 años de edad.

d) Tasa de paro calificados: población desocupada que tiene 15 o más años de escolaridad.

e) Tasa de paro semi-calificados: población desocupada que tiene entre 10 y 14 años de escolaridad.

f) Tasa de paro no calificados: población desocupada que tiene entre 0 y 9 años de escolaridad. 
IV. Desigualdad en ingresos (DING). Indica el nivel salarial que percibe la población ocupada según su edad.

a) Nivel de salario medio: salario medio por hora que perciben hombres y mujeres.

b) Índice de desigualdad salarial: desigualdad salarial de hombres y mujeres, medida a través del coeficiente de Gini ${ }^{8}$.

c) Salario medio de jóvenes: salario medio por hora que perciben trabajadores menores de 25 años de edad.

d) Salario medio de adultos: salario medio por hora que perciben los trabajadores mayores de 25 años de edad.

V. Desigualdad sectorial y ocupacional (DSO). La forma en que los hombres y mujeres se distribuyen entre las diversas ocupaciones o sectores económicos constituye, en gran medida, la desigualdad de género tanto en términos del número de empleos como de su calidad.

a) Índice de disimilitud ${ }^{9}$ : índice de segregación sectorial para medir las diferencias entre hombres y mujeres.

b) Tasas de representación: considera la tasa de participación en cada sector de actividad y la tasa de participación en la fuerza laboral, tanto para hombres como para mujeres.

c) Distribución de empleos de alta calificación: proporción de hombres y mujeres ocupados en empleos que requieren alto nivel de calificación.

d) Distribución en empleos de baja calificación: proporción de hombres y mujeres ocupados en empleos que requieren bajo nivel calificación.

VI. Informalidad laboral (IL). Cuantifica la proporción de hombres y mujeres que labora en el sector informal, no puede hacer

8 Índice de desigualdad salarial que alcanza valores entre 0 y 1 , donde cero corresponde a perfecta igualdad y uno implica total desigualdad. Se estima mediante la siguiente formula:

$$
G=\frac{1}{2 n^{2} \mu} \sum_{i=1}^{m} \sum_{j=1}^{m}\left|y_{i}-y_{j}\right|
$$

Dónde $G$ es el coeficiente de Gini; $n$ es el tamaño de la población; $y_{i}, y_{j}$ el ingreso del iésimo o j-ésimo individuo; $\mu$ es el ingreso medio y $m$ es el número de ingresos distintos. ${ }^{9} \mathrm{El}$ índice se calcula como (Duncan y Duncan, 1955):

$$
I D=\frac{1}{2} \sum_{i}\left|\frac{f_{i}}{F}-\frac{m_{i}}{M}\right|
$$

Donde: $f_{i}$ es el número de mujeres en el sector $i, m_{i}$ es el número de hombres en el sector $i ; F$ número de mujeres en la fuerza laboral, y $M$ número de hombres en la fuerza laboral. 
efectivos ciertos derechos laborales o no tiene acceso a instituciones de salud.

a) Tasa de población ocupada sin prestaciones laborales: población ocupada sin prestaciones laborales de ley (aguinaldo, vacaciones con goce de sueldo y reparto de utilidades).

b) Tasa de población ocupada sin acceso a instituciones de salud: población ocupada sin acceso a instituciones de salud.

c) Tasa de informalidad laboral: población ocupada en empleos informales como primera actividad.

d) Presencia de hombres y mujeres en el sector informal: población ocupada en el sector informal por tipo de unidad económica.

VII. Precariedad laboral (PL). Incorpora la falta de ingresos o de autonomía económica, el subempleo por insuficiencia de horas y el trabajo no remunerado, indicadores importantes al caracterizar las desigualdades de género.

a) Tasa de población ocupada con insuficiencia de ingresos: población ocupada que gana hasta dos salarios mínimos.

b) Horas dedicadas al trabajo no remunerado: horas promedio al día dedicadas al trabajo no remunerado.

c) Tasa de ocupación con jornadas de tiempo marginal: población ocupada que trabaja menos de 15 horas semanales.

d) Tasa de población ocupada sin pago: población ocupada que no recibe ningún tipo de pago (monetario o en especie) por su ocupación.

\subsubsection{Estimación del índice de desigualdad laboral}

En la figura 1 se resumen las 32 variables agrupadas en 7 componentes. Las variables consideradas se estimaron para hombres, mujeres y el total de la población de cada una de las 32 ciudades urbanas de México (ver figura 2). 
Figura 1. Índice de desigualdad laboral y sus componentes.

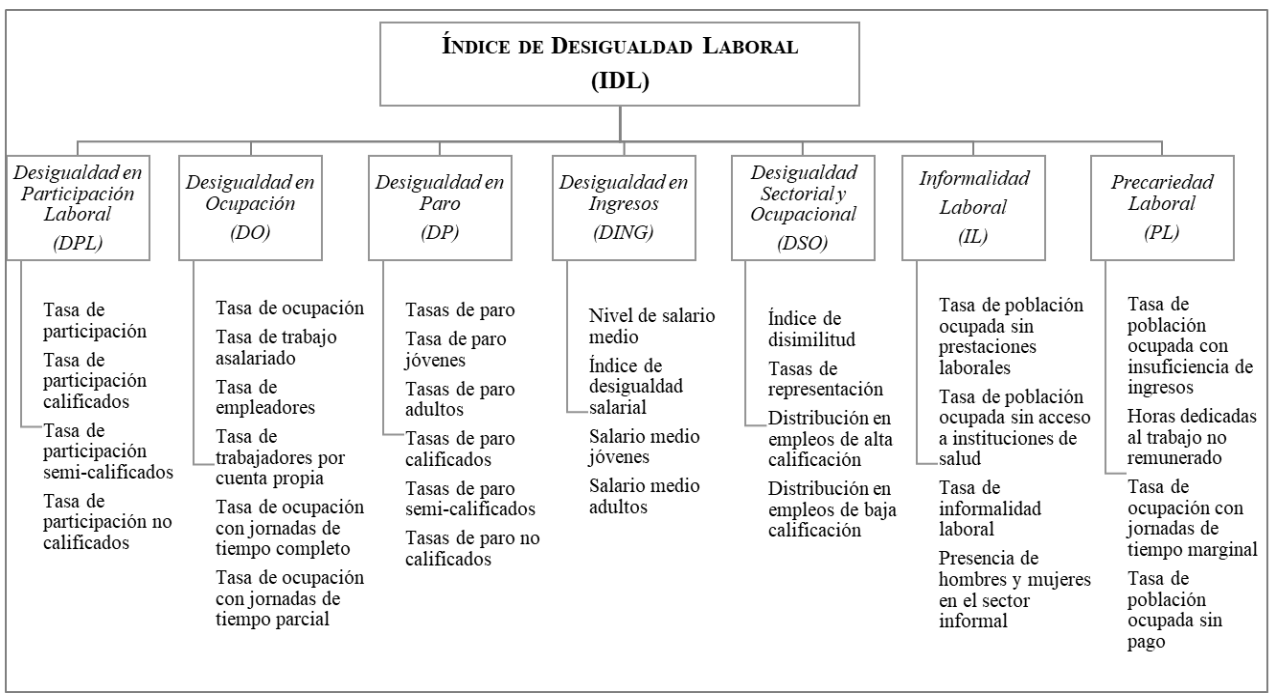

Fuente: Elaboración propia.

Con el fin de contrastar la información disponible por género y esté acotada en el mismo intervalo de variación, se optó por calcular el índice de feminización. Definido como el porcentaje que representan las mujeres con respecto al total de la variable (Riobóo y Martín, 2010), y se expresa mediante la siguiente fórmula:

$$
I F\left(X_{i t}\right)=\frac{X_{i t}^{M}}{X_{i t}^{T}} * 100
$$

Donde $I F\left(X_{i t}\right)$ es el índice de feminización de la variable $X_{i}$ para el periodo $t ; X_{i t}^{M}$ es el porcentaje que representa la variable $X_{i}$ referida a las mujeres $(M)$, y $X_{i t}^{T}$ el total de la variable $X_{i}$ para ambos sexos $(T)$. El rango de variación del índice de feminización será en el intervalo [0, 100], donde un valor igual a 50 implica equidad de género, un valor inferior a 50 sugiere una infrarrepresentación de las mujeres y una cifra superior a 50 indica una situación de feminización, lo cual sería positivo o negativo dependiendo de la variable a estudiar. En el caso de las variables donde el total no sea la suma de géneros, se reescalan en el intervalo [0, 100].

En seguida, los resultados de cada uno de los índices de feminización para las 32 ciudades urbanas de México se normalizan para eliminar las diferentes escalas y unidades de medida. Para ello, se estandarizan con 
la distancia al valor máximo y mínimo; de manera que, cuando el índice sea benéfico para el IDL se estandariza de la siguiente forma:

$$
\widehat{I F}_{i j}=\left(\frac{I F_{i j}-I F_{\text {imin }}}{I F_{\text {imáx }}-I F_{\text {imin }}}\right) \times 100
$$

En los índices con impacto negativo para el IDL el procedimiento para estandarizar las variables es el siguiente:

$$
\widehat{I F}_{i j}=\left(\frac{I F_{i j}-I F_{\text {imáx }}}{I F_{\text {imin }}-I F_{\text {imáx }}}\right) \times 100
$$

Donde: $\widehat{I F}_{j}$ es el valor estandarizado del índice de feminización de la variable $i$ en la ciudad $j ; I F_{i j}$ es el valor del índice de feminización de la variable $i$ en la ciudad $j$ en determinado momento; $I F_{\text {jmin }}$ es el valor mínimo que toma la variable $i, I F_{\text {imáx }}$ es el valor máximo que toma la variable $i$. En este sentido, mayores valores de los índices normalizados están indicando mejor situación de la mujer en el mercado laboral.

Una vez que todos los datos de las variables estén entre el rango $[0,100]$ se calculan los índices compuestos para cada uno de los siete componentes del IDL, con el fin de que se interpreten de manera igual: cuanto más elevado es su valor, mayor participación positiva de la mujer en el mercado laboral. Posteriormente, se obtienen las ponderaciones $\alpha_{i}$ correspondientes a los componentes $C_{i}$ (con $\left.i=1, \ldots, 7\right)$ y se combinan para crear el índice de desigualdad laboral para cada una de las áreas urbanas de México:

$$
I D L_{i t}=\sum_{i=1}^{n} \alpha_{i} \widehat{I F}\left(C_{i}\right)
$$

Donde $I D L_{i t}$ es el índice de desigualdad laboral para el área urbana i en el periodo t, $\widehat{I F}\left(C_{i}\right)$ son los índices de feminización normalizados que integran el componente $i$, y $\alpha_{i}$ son las ponderaciones, de modo que $\sum_{i=1}^{n} \alpha_{i}=1$ y $0 \leq \alpha_{i} \leq 1$. Cabe señalar que, para obtener la clasificación general del índice de desigualdad salarial a cada componente se le asignó una importancia igual, aunque reconocemos que los lectores pueden atribuir otras ponderaciones a las distintas variables del mercado laboral. 


\subsection{Fuente de información}

La aproximación cuantitativa del índice de desigualdad salarial se realiza con datos de la ENOE tercer trimestre de 2005 y 2016, que elabora el Instituto Nacional de Estadística y Geografía (INEGI). Para obtener la representatividad de la población se aplica el factor de expansión que proporciona dicha encuesta. En el análisis se considera la información de 32 áreas urbanas que se exhiben en el mapa 1, cada una perteneciente a una entidad de la república mexicana. De manera que para el año 2005 se trabajó con un total de 107'342,640 observaciones, en tanto que para el año 2016 la muestra fue de 122'461,977 observaciones.

\section{Mapa 1. Áreas urbanas de México analizadas.}

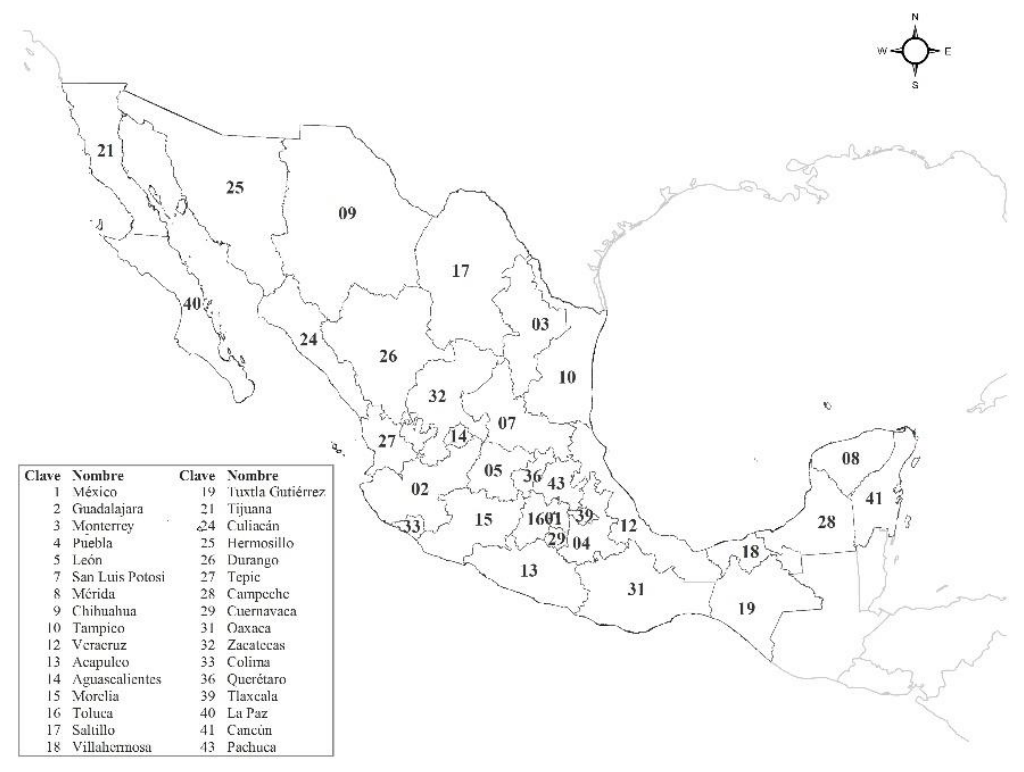

Fuente: Elaboración propia.

En el caso de las variables que integran el componente DING, la variable de análisis es el salario por hora, por lo que el salario mensual registrado en la ENOE se deflacta con el índice nacional de precios al consumidor (INPC) del mes de agosto a base $2016^{10}$.

\footnotetext{
10 El salario mensual deflactado será dividido entre 4.3 veces, el número usual de horas
} trabajadas por semana, para estimar el salario por hora. 
Con base en la clasificación de ocupaciones que se presenta en el estudio de Aguilera y Castro (2017), se definen los empleos intensivos en alta y baja calificación. Adicionalmente, la población femenina y masculina se cataloga en no calificados (NC) si tienen entre 0 y 9 años de escolaridad, semi calificados (SC) si tienen entre 10 y 14 años de escolaridad, y calificados (C) con 15 o más años de escolaridad.

\section{Análisis de resultados: desigualdad laboral en las áreas urbanas de México}

En esta sección se exhiben los resultados obtenidos en el índice de desigualdad laboral para las áreas urbanas de México, contrastando los años 2005 y 2016. El objetivo es especificar en qué áreas y aspectos del mercado laboral es necesario enfocar los esfuerzos de política pública para beneficiar a la población femenina y masculina de manera más equitativa. A partir de los valores del índice de desigualdad laboral que se resumen en la gráfica 1, se observa que las condiciones no son homogéneas entre las ciudades urbanas mexicanas. Aunque en todos los casos se produce una brecha negativa en la participación de la mujer en el mercado de trabajo, expresada mediante el IDL con valores inferiores a 50 .

Gráfico 1. Índice de desigualdad laboral por áreas urbanas, México, 2005 y 2016.

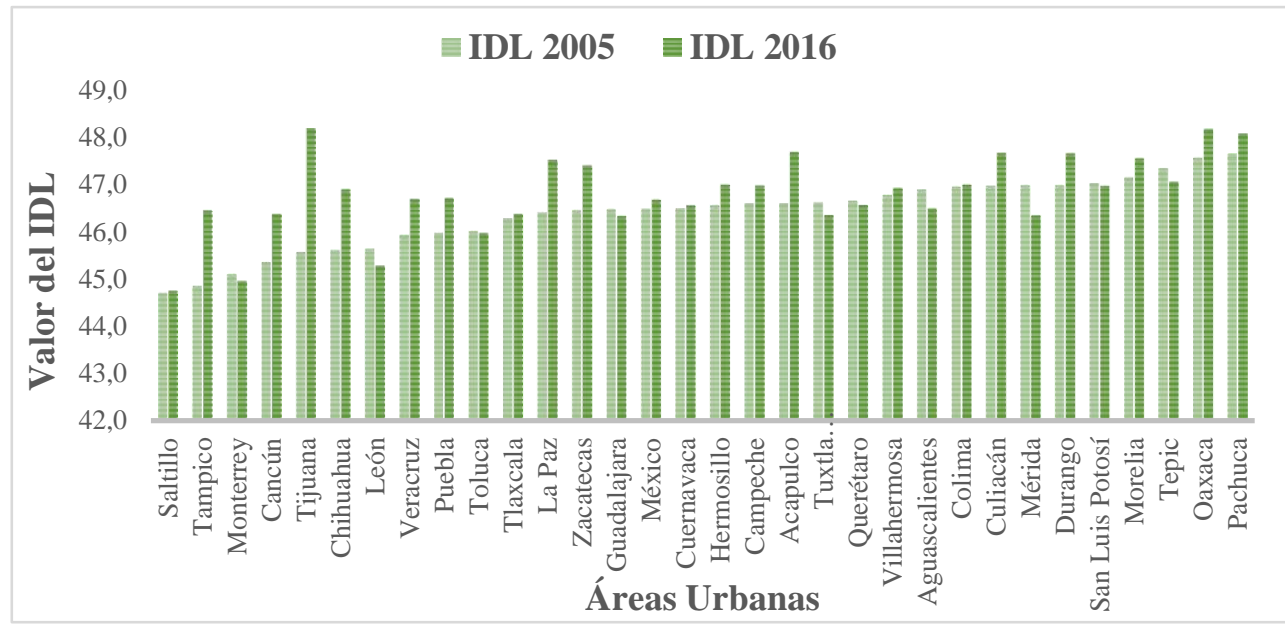

Fuente: Elaboración propia con datos del INEGI, Encuesta Nacional de Ocupación y Empleo (ENOE) 2005 y 2016, tercer trimestre de cada año. 
El promedio de las áreas urbanas en el año 2005 fue de 46.4, con valores que oscilan entre 44.7 y 47.65 para Saltillo y Pachuca, ciudades con menor y mayor índice de equidad laboral por género respectivamente. En 2016, el índice promedio aumentó marginalmente a 46.8 y Saltillo continuó como la ciudad con menor índice de equidad laboral (44.75), mientras que Tijuana se presenta como el área urbana con mayor índice (48.19). Al comparar estos resultados con los observados en otros estudios como el de Riobóo y Martín (2010), quienes propusieron una medición de la desigualdad laboral por género para la comunidad Castilla-La Mancha y España durante el periodo 2002-2009, se puede apreciar que el nivel de desigualdad laboral por género es mayor que el observado en las 32 áreas urbanas de México.

El contraste a lo largo del periodo de estudio evidencia que la condición negativa de la mujer en el mercado de trabajo se ha atenuando en algunas ciudades ${ }^{11}$, aunque en otras se observa una menor igualdad ${ }^{12}$ (gráfico 2). Pese a lo anterior, en términos generales se puede decir que las áreas urbanas de México han avanzado hacia una mayor equidad de género en el mercado laboral.

11 Tal es el caso de Tijuana, Tampico, Cancún, Chihuahua, La Paz, Zacatecas, Acapulco, Culiacán, Veracruz, Puebla, Durango, Oaxaca, Hermosillo, Campeche, Morelia y Pachuca.

12 Mérida, Aguascalientes, León Tepic, Tuxtla Gutiérrez, Monterrey, Guadalajara y Querétaro. 


\section{Gráfico 2. Variación porcentual del IDL por áreas urbanas,} México, 2005-2016.

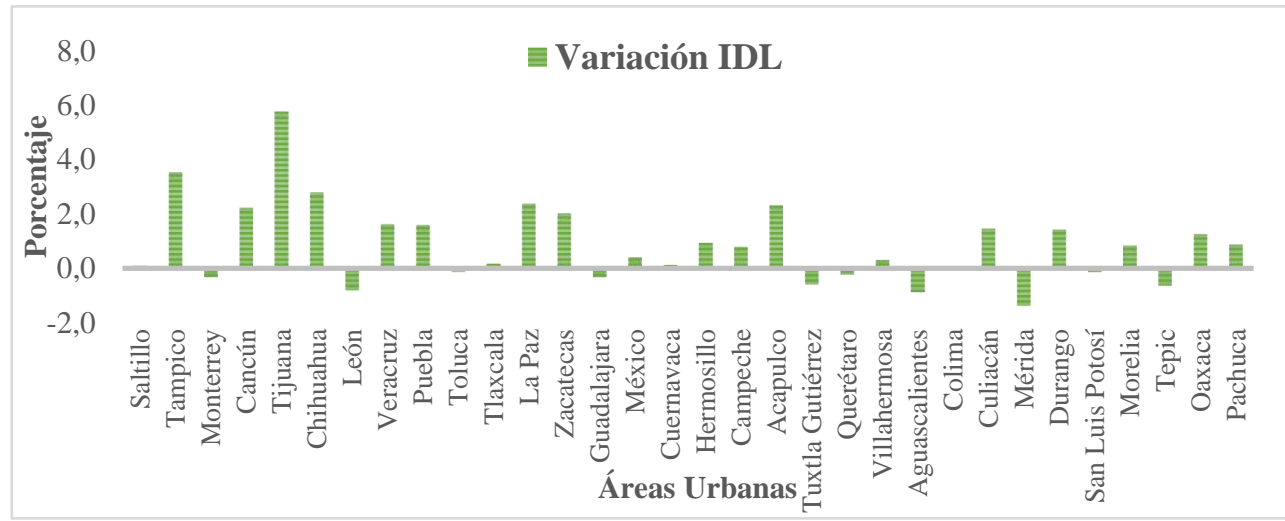

Fuente: Elaboración propia con datos del INEGI, Encuesta Nacional de Ocupación y Empleo (ENOE) 2005 y 2016, tercer trimestre de cada año.

La identificación de los niveles de desigualdad laboral por género a nivel individual lleva a preguntarnos si el comportamiento del IDL puede estar vinculado con algún patrón espacial, estructura sectorial o desempeño económico. Al respecto, en el mapa 2 (a y b) se representan los IDL ${ }^{13}$ para los años 2005 y 2016 , de los cuales se pueden destacar dos elementos: i) en general se presenta una mejoría en las condiciones de equidad laboral por género durante el periodo de observación, y ii) el comportamiento del IDL no parece mostrar un determinado patrón espacial, dado que, tanto en ciudades del norte como las del sur se aprecian elevados niveles de inequidad laboral por género.

13 En el mapa se ilumina la totalidad del estado (unidad sub-nacional), aunque la información corresponde a la ciudad ubicada en el estado. 
Mapa 2. Índice de desigualdad laboral por áreas urbanas, México, 2005 y 2016.

a) $\mathbf{2 0 0 5}$

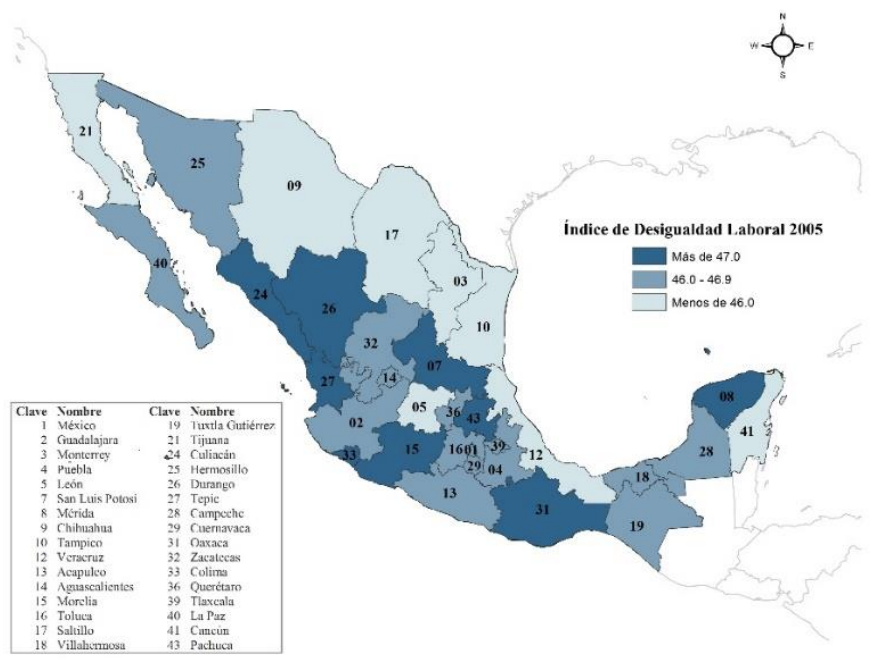

b) 2016

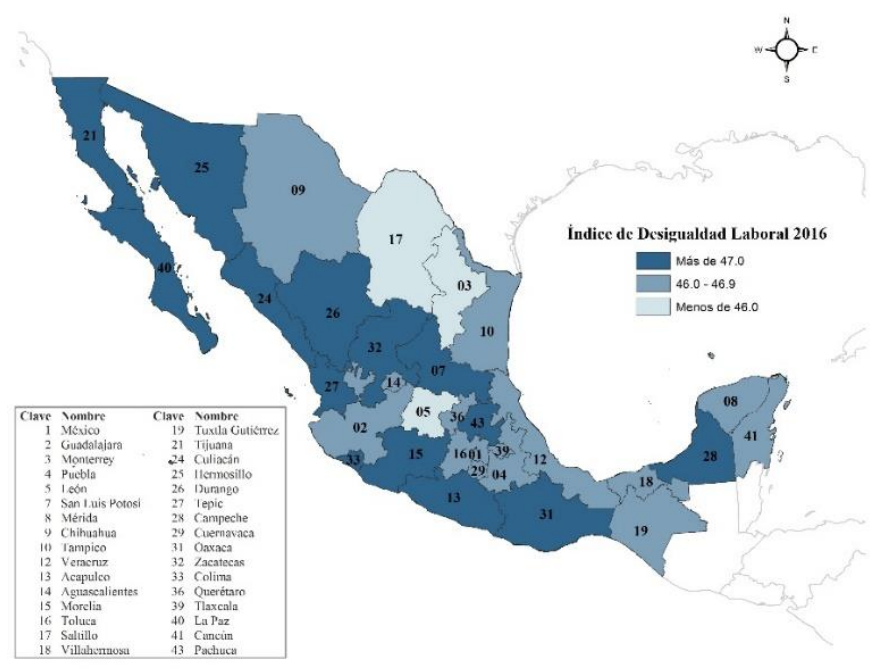

Fuente: Elaboración propia.

Dado que no se puede considerar alguna concentración espacial, valdría la pena examinar un posible vínculo entre el nivel de desigualdad laboral por género y el desempeño económico, la estructura sectorial y la 
participación femenina de las áreas urbanas mexicanas. De ahí que, la tabla 1 presenta la correlación entre el IDL y variables seleccionadas. Al respecto, los resultados indican que el IDL no está correlacionado con el salario promedio por hora de las ciudades; sin embargo, las áreas urbanas con mayor presencia de empleo manufacturero sí exhiben una relación negativa con la equidad laboral por género, hecho que se refuerza en el tiempo. Finalmente, la mayor presencia de mujeres en el sector servicios se asocia con mayor igualdad laboral, aunque el efecto se reduce en el tiempo.

Tabla 1. Correlación del índice de desigualdad laboral con variables seleccionadas, 2005 y 2016.

\begin{tabular}{lcc}
\hline & IDL 2005 & IDL 2016 \\
\hline Salario real por hora & -0.1879 & 0.0882 \\
Empleo en sector manufacturero & $-0.4401^{*}$ & $-0.4969^{*}$ \\
Presencia mujeres en sector servicios & $0.6388^{*}$ & 0.3189 \\
\hline
\end{tabular}

Fuente: Elaboración propia con datos del INEGI, Encuesta Nacional de Ocupación y Empleo (ENOE) 2005 y 2016.

Nota: *La correlación es significativa al nivel 0.05 .

Un análisis desagregado del IDL permite inferir conductas heterogéneas entre sus componentes. Aunque es importante destacar que, seis componentes indican una posición en desventaja para las mujeres y únicamente el correspondiente a informalidad es favorable (gráfica 3). En el caso de la precariedad laboral, en promedio las mujeres tienen un detrimento de aproximadamente 14 puntos en el índice con respecto a la condición de equidad; en tanto que, en el componente sectorial y ocupacional la diferencia es mínima.

Adicionalmente, el comportamiento en el tiempo resulta dispar. Ya que, si bien seis componentes exhibieron una tendencia hacia la equidad en 2016, el componente de participación laboral mostró un retroceso y se consolidó como la segunda mayor fuente de inequidad laboral por género (gráfico 3). 


\section{Gráfico 3. Componentes del índice de desigualad laboral, 2005 y 2016.}

Precariedad laboral 2016

Fuente: Elaboración propia con datos del INEGI, Encuesta Nacional de Ocupación y Empleo (ENOE) 2005 y 2016.

Los resultados obtenidos en los componentes del índice de desigualdad laboral se resumen en las tablas 2 y 3 para las 32 áreas urbanas de México. Como previamente se identificó, las mayores distancias con respecto a la equidad se dan en el componente de precariedad laboral. En particular, Cancún, León y Chihuahua exhibieron la situación menos favorable. Esto puede atribuirse a que un elevado porcentaje de mujeres obtiene una remuneración inferior a 2 salarios mínimos en relación con los hombres; las mujeres dedican mayor número de horas al trabajo no remunerado; así como al hecho que, en León y Chihuahua aproximadamente el 9 por ciento de la población femenina ocupada tiene jornadas de tiempo marginal frente al 3 por ciento que exhibió la población masculina, mientras que en Cancún alcanzó el 11 y 6 por ciento respectivamente ${ }^{14}$.

Caso contrario, la informalidad laboral se mantuvo en cifras superiores al 50 por ciento, lo que implica una posición favorable para las mujeres en relación con los hombres. Esto se debe a que, tanto en 2005 como en 2016, más del 54 por ciento del total de la mano de obra que laboró en el sector informal fueron del sexo masculino. Destacan las ciudades de Tijuana, Chihuahua y La Paz con los valores más altos del componente IL (tabla 2 y 3 ).

14 Debido a limitaciones de espacio, no se presenta la información correspondiente a cada variable; no obstante, se encuentra disponible para quién la solicite. 
Aguilera y Castro / Revista de Economía Laboral 14(2) (2017), 169-199

Tabla 2. Índice de desigualdad laboral y sus componentes por áreas urbanas, México, 2005.

\begin{tabular}{|c|c|c|c|c|c|c|c|c|}
\hline Área Urbana & $\begin{array}{c}\text { Desigualdad en } \\
\text { participación laboral }\end{array}$ & $\begin{array}{l}\text { Desigualdad } \\
\text { en ocupación }\end{array}$ & $\begin{array}{l}\text { Desigualdad } \\
\text { en paro }\end{array}$ & $\begin{array}{l}\text { Desigualdad } \\
\text { en ingresos }\end{array}$ & $\begin{array}{c}\text { Desigualdad sectorial } \\
\text { y ocupacional }\end{array}$ & Informalidad & $\begin{array}{l}\text { Precariedad } \\
\text { laboral }\end{array}$ & $\begin{array}{l}I D L \\
2005\end{array}$ \\
\hline México & 40.857 & 46.542 & 48.472 & 49.997 & 49.836 & 54.142 & 35.527 & 46.482 \\
\hline Guadalajara & 42.278 & 45.380 & 49.109 & 48.018 & 51.726 & 53.274 & 35.544 & 46.476 \\
\hline Monterrey & 40.929 & 44.806 & 47.410 & 47.903 & 47.548 & 53.397 & 33.731 & 45.103 \\
\hline Puebla & 40.417 & 45.567 & 48.525 & 47.408 & 49.147 & 53.768 & 37.000 & 45.976 \\
\hline León & 41.218 & 47.504 & 48.456 & 47.539 & 50.181 & 52.357 & 32.224 & 45.640 \\
\hline San Luis Potosí & 42.652 & 46.267 & 49.041 & 49.486 & 52.098 & 52.605 & 37.013 & 47.023 \\
\hline Mérida & 42.069 & 46.632 & 48.802 & 49.297 & 51.036 & 53.379 & 37.642 & 46.980 \\
\hline Chihuahua & 40.713 & 44.139 & 44.259 & 47.942 & 50.866 & 58.507 & 32.881 & 45.615 \\
\hline Tampico & 39.405 & 45.914 & 49.957 & 46.465 & 46.682 & 50.622 & 34.934 & 44.854 \\
\hline Veracruz & 40.708 & 47.530 & 50.007 & 47.861 & 49.391 & 52.476 & 33.531 & 45.929 \\
\hline Acapulco & 40.421 & 46.362 & 49.836 & 48.614 & 48.339 & 54.210 & 38.449 & 46.604 \\
\hline Aguascalientes & 41.171 & 48.136 & 49.350 & 50.016 & 50.081 & 56.179 & 33.316 & 46.893 \\
\hline Morelia & 42.790 & 46.280 & 48.268 & 47.469 & 52.049 & 54.819 & 38.380 & 47.151 \\
\hline Toluca & 39.469 & 46.801 & 49.834 & 49.100 & 47.875 & 54.882 & 34.133 & 46.013 \\
\hline Saltillo & 38.667 & 45.744 & 47.491 & 47.738 & 45.556 & 52.914 & 34.814 & 44.704 \\
\hline Villahermosa & 41.701 & 48.129 & 49.106 & 48.457 & 50.897 & 54.659 & 34.494 & 46.778 \\
\hline Tuxtla Gutiérrez & 41.499 & 47.885 & 49.191 & 48.008 & 48.602 & 53.702 & 37.422 & 46.615 \\
\hline Tijuana & 37.904 & 44.665 & 41.684 & 47.042 & 48.846 & 60.587 & 38.232 & 45.566 \\
\hline Culiacán & 42.991 & 46.199 & 49.589 & 46.882 & 51.116 & 53.788 & 38.258 & 46.975 \\
\hline Hermosillo & 41.782 & 45.258 & 48.583 & 49.068 & 49.657 & 53.240 & 38.294 & 46.555 \\
\hline Durango & 41.320 & 45.758 & 50.363 & 48.588 & 48.968 & 54.321 & 39.548 & 46.981 \\
\hline Tepic & 43.866 & 47.572 & 48.359 & 46.872 & 54.120 & 51.726 & 38.901 & 47.345 \\
\hline Campeche & 42.759 & 46.346 & 49.585 & 49.099 & 48.788 & 52.863 & 36.780 & 46.603 \\
\hline Cuernavaca & 41.155 & 47.142 & 49.124 & 48.750 & 50.318 & 53.941 & 35.013 & 46.492 \\
\hline Oaxaca & 44.315 & 48.271 & 51.792 & 46.939 & 51.824 & 51.618 & 38.190 & 47.564 \\
\hline Zacatecas & 41.657 & 46.060 & 47.416 & 48.219 & 49.977 & 54.486 & 37.361 & 46.454 \\
\hline Colima & 43.607 & 48.248 & 48.781 & 48.218 & 50.584 & 54.875 & 34.392 & 46.958 \\
\hline Querétaro & 42.103 & 47.406 & 48.246 & 47.644 & 51.400 & 53.206 & 36.581 & 46.655 \\
\hline Tlaxcala & 41.735 & 43.168 & 47.411 & 47.994 & 48.634 & 54.413 & 40.635 & 46.284 \\
\hline La Paz & 41.219 & 46.045 & 50.118 & 48.823 & 47.638 & 56.088 & 34.907 & 46.405 \\
\hline Cancún & 41.951 & 49.394 & 46.728 & 47.668 & 46.528 & 54.237 & 30.986 & 45.356 \\
\hline Pachuca & 43.439 & 46.738 & 49.540 & 47.843 & 51.850 & 54.483 & 39.652 & 47.649 \\
\hline
\end{tabular}

Fuente: Elaboración propia con datos del INEGI, Encuesta Nacional de Ocupación y Empleo (ENOE) 2005, tercer trimestre.

(C) Revista de Economía Laboral 
Tabla 3. Índice de desigualdad laboral y sus componentes por áreas urbanas, México, 2016.

\begin{tabular}{|c|c|c|c|c|c|c|c|c|}
\hline Área Urbana & $\begin{array}{c}\text { Desigualdad en } \\
\text { participación laboral }\end{array}$ & $\begin{array}{c}\text { Desigualdad en } \\
\text { ocupación }\end{array}$ & $\begin{array}{l}\text { Desigualdad } \\
\text { en paro }\end{array}$ & $\begin{array}{c}\text { Desigualdad } \\
\text { en ingresos }\end{array}$ & $\begin{array}{c}\text { Desigualdad sectorial } \\
\text { y ocupacional }\end{array}$ & Informalidad & $\begin{array}{c}\text { Precariedad } \\
\text { laboral }\end{array}$ & $\begin{array}{l}I D L \\
2016\end{array}$ \\
\hline México & 39.746 & 49.090 & 50.616 & 49.167 & 49.613 & 53.561 & 34.919 & 46.673 \\
\hline Guadalajara & 38.538 & 46.385 & 51.370 & 48.289 & 51.306 & 51.507 & 36.888 & 46.326 \\
\hline Monterrey & 38.001 & 46.962 & 48.633 & 48.316 & 46.095 & 51.646 & 35.033 & 44.955 \\
\hline Puebla & 38.168 & 46.607 & 50.523 & 50.463 & 50.094 & 53.307 & 37.810 & 46.710 \\
\hline León & 39.528 & 47.842 & 47.950 & 47.773 & 49.581 & 52.641 & 31.624 & 45.277 \\
\hline San Luis Potosí & 40.385 & 48.774 & 50.095 & 48.485 & 52.318 & 51.116 & 37.581 & 46.965 \\
\hline Mérida & 40.774 & 48.107 & 48.952 & 49.164 & 50.073 & 52.048 & 35.240 & 46.337 \\
\hline Chihuahua & 39.863 & 44.636 & 49.625 & 48.789 & 50.946 & 59.867 & 34.499 & 46.889 \\
\hline Tampico & 39.559 & 48.016 & 52.009 & 47.926 & 47.504 & 52.542 & 37.553 & 46.444 \\
\hline Veracruz & 39.181 & 47.270 & 50.250 & 48.843 & 49.875 & 53.439 & 37.883 & 46.677 \\
\hline Acapulco & 41.350 & 48.224 & 52.091 & 49.318 & 49.356 & 53.276 & 40.144 & 47.680 \\
\hline Aguascalientes & 39.373 & 48.765 & 50.835 & 48.945 & 50.320 & 52.074 & 35.087 & 46.486 \\
\hline Morelia & 41.001 & 47.371 & 49.749 & 49.271 & 51.945 & 55.731 & 37.749 & 47.545 \\
\hline Toluca & 37.371 & 47.177 & 50.565 & 48.207 & 49.738 & 55.510 & 33.173 & 45.963 \\
\hline Saltillo & 38.251 & 47.069 & 49.520 & 49.557 & 45.266 & 51.692 & 31.879 & 44.748 \\
\hline Villahermosa & 39.968 & 47.667 & 49.643 & 51.349 & 50.757 & 53.698 & 35.370 & 46.922 \\
\hline Tuxtla Gutiérrez & 38.630 & 47.167 & 51.581 & 48.386 & 50.067 & 53.355 & 35.220 & 46.344 \\
\hline Tijuana & 39.536 & 48.827 & 50.042 & 49.521 & 49.563 & 58.110 & 41.744 & 48.192 \\
\hline Culiacán & 41.714 & 46.012 & 50.134 & 49.060 & 51.761 & 54.906 & 40.012 & 47.657 \\
\hline Hermosillo & 40.916 & 45.624 & 49.346 & 49.648 & 49.354 & 53.636 & 40.427 & 46.993 \\
\hline Durango & 40.756 & 49.607 & 50.988 & 49.818 & 49.696 & 54.179 & 38.493 & 47.648 \\
\hline Tepic & 42.831 & 47.472 & 47.444 & 48.098 & 53.128 & 51.163 & 39.214 & 47.050 \\
\hline Campeche & 39.066 & 47.631 & 51.782 & 51.452 & 49.383 & 52.723 & 36.780 & 46.974 \\
\hline Cuernavaca & 39.694 & 47.064 & 52.330 & 48.409 & 50.100 & 54.023 & 34.206 & 46.546 \\
\hline Oaxaca & 42.801 & 48.971 & 49.035 & 49.116 & 52.198 & 53.407 & 41.626 & 48.165 \\
\hline Zacatecas & 40.599 & 46.982 & 49.685 & 50.088 & 50.501 & 53.690 & 40.233 & 47.397 \\
\hline Colima & 42.336 & 47.298 & 47.579 & 47.431 & 51.071 & 54.096 & 39.093 & 46.986 \\
\hline Querétaro & 39.480 & 49.821 & 50.985 & 48.520 & 51.580 & 52.122 & 33.370 & 46.554 \\
\hline Tlaxcala & 39.382 & 44.565 & 48.253 & 51.742 & 48.898 & 53.887 & 37.834 & 46.366 \\
\hline $\mathrm{La} \mathrm{Paz}$ & 41.088 & 48.739 & 49.510 & 47.910 & 48.063 & 56.422 & 40.819 & 47.507 \\
\hline Cancún & 39.021 & 49.268 & 49.418 & 49.366 & 46.800 & 55.896 & 34.791 & 46.366 \\
\hline Pachuca & 41.678 & 49.376 & 50.887 & 50.627 & 51.786 & 53.707 & 38.384 & 48.064 \\
\hline
\end{tabular}

Fuente: Elaboración propia con datos del INEGI, Encuesta Nacional de Ocupación y Empleo (ENOE) 2016, tercer trimestre. 
En otro orden de ideas, la transición demográfica de México se ha considerado como uno de los principales factores del heterogéneo crecimiento de la oferta laboral regional. Su impacto se ha reflejado a través de dos ópticas: el crecimiento de la población en edad de trabajar y el crecimiento de la población en edades activas que demandan empleo (Hernández, 2004). En este contexto, el componente de desigualdad en participación muestra una reducción de 2005 al 2016, por lo que es necesario hacer algunas aclaraciones sobre las variables que lo integran.

Si bien se han presentado cambios significativos en la oferta total de la mano de obra femenina, aún persisten importantes desigualdades de género. En el año 2005, la tasa de participación de las mujeres en León, Toluca, Saltillo y Tijuana equivale, en promedio, a la mitad de la de hombres; en 2016, la tasa de participación de las mujeres en Toluca, Saltillo, Monterrey y Puebla equivale, en promedio, a menos del 59 por ciento de la correspondiente a hombres, y en las ciudades donde la brecha es menor, la tasa de participación femenina no alcanza el 75 por ciento de la masculina.

La distinción de la tasa de participación por nivel de calificación permite identificar que las brechas disminuyeron con el incremento en los años de escolaridad. El promedio ponderado de la tasa de participación de las mujeres calificadas de las 32 áreas urbanas de México equivalía en 2005 al 82 por ciento de la masculina, y se elevó al 85 por ciento en 2016. Mientras que, el promedio ponderado de la tasa de participación de las mujeres no calificadas pasó de 80 por ciento de la masculina en 2005, a 55 por ciento en 2016.

Por el lado de la demanda laboral, un cambio notable es la reducción de las brechas de empleo: el promedio ponderado de la tasa de ocupación femenina de las 32 ciudades urbanas de México equivalía en 2005 al 58 por ciento de la masculina, y se elevó al 65 en el 2016. Al respecto, es importante aclarar que la población femenina es la que se encuentra mayormente empleada en jornadas de tiempo parcial. Prueba de ello es que, la tasa de ocupación en jornadas de tiempo parcial de los hombres corresponde en promedio menos de la mitad de la tasa femenil y, en las áreas donde la brecha es menor, la tasa de ocupación en jornada de tiempo parcial masculina no alcanza el 50 por ciento de la femenina.

Continuando con el análisis del empleo, a través del componente desigualdad sectorial y ocupacional se identificó a Chihuahua y Tijuana como las ciudades con menor índice de disimilitud (inferior a 0.23), esto involucra que su población ocupada se encuentra distribuida entre sus sectores económicos de manera más igualitaria. Paradójicamente, Tampico, Acapulco y Veracruz exhibieron el índice de disimilitud más

(C) Revista de Economía Laboral 
alto, lo que conlleva una mayor segregación ocupacional ${ }^{15}$. Lo anterior es relevante, ya que la concentración relativa de mujeres en determinado sector de actividad puede traer consigo consecuencias significativas en sus niveles de ingreso, las posibilidades de movilidad, de carrera laboral, entre otros aspectos (Ariza, 2006).

Lo discutido hasta ahora permite inferir que, el aumento de las tasas de participación y empleo estuvo acompañado de una reducción en el ingreso salarial. Dado que, el promedio ponderado del salario medio por hora para las 32 áreas urbanas de México fue de 43.4 pesos para hombres y 38.7 pesos para mujeres en 2005; mismo que se redujo 11.6 por ciento en los hombres y 4.4 por ciento en las mujeres en el 2016. Cabe señalar que, aunque la caída en el nivel salarial impactó en menor magnitud sobre las trabajadoras femeninas, en general perciben un salario inferior al de los hombres.

El examen del nivel de ingreso laboral por años de edad reflejó que, la reducción en el salario impactó en mayor magnitud sobre los trabajadores adultos de 25 años y más. Ya que, el salario medio de los hombres pasó de 47.9 a 41.8 pesos mexicanos de 2005 a 2016 y, en el caso de las mujeres pasó de 42.0 a 38.7 pesos. En el mismo sentido, los resultados del índice de desigualdad salarial arrojaron un valor del coeficiente de Gini de 0.4095 para los hombres y de 0.4190 para mujeres, como promedio ponderado para las áreas urbanas en el 2005; el cual decreció en 2016 a 0.3740 y 0.3877 respectivamente. Por otro lado, el comparativo entre áreas permitió identificar a la ciudad de México, Tuxtla Gutiérrez y Pachuca como las ciudades con mayor desigualad salarial en el 2016, mientras que las más equitativas fueron León, Toluca y Cuernavaca.

Finalmente, del componente desigualdad en paro se pueden discutir algunos aspectos. En primer lugar, las mujeres resultaron en desventaja con una tasa de paro promedio de 4.6 y 4.4 por ciento en 2005 y 2016 ; en tanto que, la tasa de paro para los hombres aumentó de 4.1 a 4.3 por ciento. En ambos casos, las variaciones en el desempleo afectaron a la mano de obra adulta (25 años y más).

Aunado a lo anterior, la población con más de 10 años de escolaridad se ve desfavorecida en el desempleo si se trata de mujeres y aquellos con menos de 10 años de escolaridad se ven principalmente afectados por el desempleo si son hombres.

\footnotetext{
15 En Tampico, Acapulco y Veracruz, la construcción, el comercio y los transportes resultaron sectores clave para el empleo de los hombres; para las mujeres fueron el comercio, servicios de alojamiento y servicios sociales.
} 


\section{Conclusiones}

El objetivo del trabajo consistió en examinar la desigualdad laboral desde la perspectiva de género, con la finalidad de identificar las oportunidades y desafíos que enfrentan las áreas urbanas de México. Para ello, con datos de la Encuesta Nacional de Ocupación y Empleo (ENOE) 2005 y 2016, se construyó un índice de desigualdad laboral integrado, a su vez, por componentes específicos que facultan valorar la composición del mercado laboral entre formal e informal, participación de hombres y mujeres en la fuerza de trabajo, presencia en empleos según el nivel de calificación, brecha salarial por razón de género, desempleo, segregación ocupacional, diferencias en jornadas de trabajo y precariedad laboral.

El contraste entre los años 2005 y 2016 muestra que, a nivel agregado se ha avanzado hacia una equidad de género en el mercado de trabajo mexicano; sin embargo, un análisis a detalle reveló que las condiciones no son homogéneas entre las áreas urbanas de México. En particular, se aprecia que en Pachuca, Oaxaca y Tepic existe una menor distancia hacia la igualdad de género.

Aun cuando el IDL no parece mostrar un determinado patrón espacial, el análisis de correlación indica una relación negativa entre la presencia de actividades manufactureras en las ciudades y la igualdad laboral por género. De ahí que, Saltillo, Monterrey y León se identificaron como las ciudades urbanas que requieren mayor atención y mejora laboral.

El análisis para cada uno de los componentes del IDL reveló que, si bien se han evidenciado incrementos significativos en la participación de la mano de obra femenina en la fuerza laboral de México, en algunas dimensiones presenta condiciones relativas desfavorables. Existe una mayor proporción de mujeres que perciben un ingreso salarial inferior a dos salarios mínimos, dedican más de 35 horas a la semana al trabajo no remunerado o laboran en jornadas remuneradas inferiores a 15 horas semanales.

Por otra parte, los principales hallazgos exhiben que la informalidad tiene mayor incidencia negativa sobre la población masculina en comparación con la femenina, producto de su presencia en el sector informal, así como por la falta de prestaciones laborales y acceso a instituciones de salud.

Finalmente, es pertinente señalar que el presente documento constituye un avance en el conocimiento de la desigualdad del mercado laboral por género en las áreas urbanas de México. Del cual, se deriva la 
necesidad de implementar políticas públicas focalizadas que atiendan los diferentes aspectos en los cuales existe mayor brecha laboral por género, con la finalidad de afrontar los desafíos actuales: generar oportunidades de participación y capacidades laborales equitativas para mujeres y hombres, transformar las relaciones de género en la sociedad y en el trabajo, alcanzar una globalización justa y combatir la desigualdad, exclusión social y pobreza.

Avanzar en el análisis de la brecha laboral por género y su vinculación con factores espaciales, estructuras sectoriales y coyunturales, entre otros, puede ser motivo de futuras investigaciones, así como explorar la brecha laboral a la luz de aspectos específicos como pueden ser apertura económica y cambio tecnológico, por mencionar algunos.

\section{Bibliografía}

Aguayo, E., Airola, J. y Juhn, C. (2010), "Did trade liberalization help women? The case of Mexico in the 1990s", National Bureau of Economic Research.

Aguilera, A. y Castro, D. (2017). "Calificación laboral y desigualdad salarial; un ejercicio metodológico por conglomerados", mimeo.

Arceo, O. y Campos, M. (2014), “Evolución de la brecha salarial de género en México”, El Trimestre Económico, 81(323), 619-653.

Ariza, M. (2006), "Mercados de trabajo urbanos y desigualdad de género en México a principios del siglo XXI”, La situación del trabajo en México, 377-411.

Blecker, A. (2010), La competencia china y la economía mexicana: consecuencias para el empleo y los salarios manufactureros (2010), México.

Bonet, R. (2004), "Desigualdades de género en el mercado laboral: un problema actual". Departament d'Economia Aplicada-Universitat de les Illes Balears. Disponible en la Web: http://dea.uib.cat/digitalAssets/128/128260_4.pdf.

Brown, J., Pagán, A., y Rodríguez, E. (1999). Occupational attainment and gender earnings differentials in Mexico. ILR Review, 53(1), 123-135.

Calonico, S., y Ñopo, H. (2009), "Gender segregation in the workplace and wage gaps: evidence from urban Mexico 1994-2004", Occupational and Residential Segregation, Emerald Group Publishing Limited, 245-270. 
Castro D. y Huesca L. (2007), "Desigualdad salarial en México: Una revisión”, Papeles de población. (54): 225-264.

Castro D., Huesca L. y Zamarrón N. (2015), "Discriminación salarial por género, en la industria manufacturera de la frontera norte de México, en el periodo 2005-2011”. Nóesis. Vol. 24 (47): 50-80.

CEPAL. (2013), "Implementación del Programa de Acción de la Conferencia Internacional sobre la Población y el Desarrollo en América Latina y el Caribe”. Examen del período 2009-2013 y lecciones aprendidas. Síntesis y balance (LC/L.3640(CRPD.1/3), Santiago.

CEPAL. (2014), "Pactos para la igualdad: hacia un futuro sostenible". (LC/G.2586(SES.35/3)), Santiago.

CEPAL. (2017), Planes de igualdad de género en América Latina y el Caribe, mapas de ruta para el desarrollo. Naciones Unidas, Santiago.

Cervantes, J. (2015), "Transformaciones del mercado de trabajo en México 1995-2014: entre la precariedad e informalidad y la heterogeneidad laboral”, Gaceta Laboral, 21(2).

Cervantes, J, y Acharya, A. (2013), "La economía formal e informal en México 1995-2012: Implicaciones para los mercados laborales." Gaceta Laboral 19.2 (2013).

Duncan O. y Duncan B. (1955), "Methodological analysis of segregation indexes", American Sociological Review, 20 (2), 210-217.

England, P. (2005), "Gender inequality in labor markets: The role of motherhood and segregation”, Social Politics: International Studies in Gender, State \& Society, 12(2), 264288.

Figueroa, E., Abarca, R., Elías, G., Soto, P. y Torres, E. (2012), Análisis del Desempleo, la Migración y la Pobreza en México.

García, B. (2009), "Los mercados de trabajo urbanos de México a principios del siglo XXI", Revista mexicana de sociología, 71(1), 5-46.

Gonas, L. (2000), "Labour Market Transformations and Changing Gender Relations: Editorial Introduction", Economic \& Industrial Democracy, 21(3), 275-282.

Hanushek, A. y Wößmann, L. (2007), "The role of education quality for economic growth", World Bank Policy Research Working Paper.

Hernández L, E. (2004), "Panorama del mercado laboral de profesionistas en México", Economía UNAM, 1(2), 98-109.

IMCO. (2014), Las reformas y los estados: La responsabilidad de las entidades en el éxito de los cambios estructurales, México. 
Martínez, D., Llamas, I. y Aboites, G. (2016), "Profesionistas e informalidad en México", en Llamas y Garro (ed.), Estado, reformas gubernamentales y desigualdad en los ingresos laborales, 215-237.

Molano, M. (2014), "Empleo y justicia laboral local: una agenda de reformas para los estados", en Las reformas y los estados. La responsabilidad de las entidades en el éxito de los cambios estructurales, 21-30.

Negrete, R. (2012), "Sector informal en México visto bajo el esquema conceptual OITGrupo de DELHI”, en Garza (ed.), La situación del trabajo en México, 2012, el trabajo en la crisis, 119-154.

OCDE. (2012), Perspectivas OCDE: México. Reformas para el cambio, OECD Publishing, París.

OCDE. (2014), Employment Outlook 2014, OECD Publishing, Paris.

OCDE. (2015a). Estudios económicos de la OCDE México, OECD Publishing, París.

OCDE. (2015b). Employment Outlook 2015, OECD Publishing, Paris.

OECD (2016), Education at a Glance 2016: OECD Indicators, OECD Publishing, Paris. http://dx.doi.org/10.1787/eag-2016-en

OCDE. (2017), Building an Inclusive Mexico, Policies and Good Governance for Gender Equality, OECD Publishing, París.

OIT. (2014), El empleo informal en México: situación actual, políticas y desafíos, Oficina Internacional del Trabajo, Ginebra.

OIT. (2016), Panorama laboral 2016. América Latina y el Caribe. OIT/Oficina regional para América Latina y el Caribe, Lima.

OIT (2017). Informe mundial sobre salarios 2016/2017. La desiguadlad en el lugar de trabajo, Oficina Internacional del Trabajo, Ginebra.

Pagán, A., y Sánchez, M. (2000), "Gender differences in labor market decisions: Evidence from rural Mexico", Economic Development and Cultural Change, 48(3), 619-637.

PNUD. (2016), Informe sobre el desarrollo humano México 2016, desigualdad y movilidad. Programa para las Naciones Unidas, México.

Popli, K. (2013), "Gender wage differentials in Mexico: a distributional approach", Journal of the Royal Statistical Society: Series A (Statistics in Society), 176(2), 295-319.

Rendón, T. y Maldonado, V. (2005), "Evolución reciente del trabajo de hombres y mujeres en México", Comercio Exterior, 55(1), 44-57.

Riobóo, I. y Martín, C. (2010), "Medición de las desigualdades de género en el mercado laboral de Castilla-La Mancha”, Clm. economía: Revista económica de Castilla-La Mancha, (17), 315-334. 
Rocha, J. (2013), “El Pacto por México bajo la lupa”, Revista análisis plural, 94-105.

Rodríguez, R. (2018), "Brecha salarial por género en México. Desde un enfoque regional, según su exposición a la apertura comercial 2005-2015”, Noesis, Vol. 27 (54): 19-38

Rodríguez, R. y Castro D. (2014a), "Discriminación salarial de la mujer en el mercado laboral de México y sus regiones”, Economía Sociedad y Territorio. XIV (46): 655-686.

Rodríguez R. y Castro D. (2014b), “Análisis de la discriminación salarial por género en Saltillo y Hermosillo: un estudio comparativo en la industria manufacturera", Nóesis. 23(46): 80-113.

Rodríguez, R. y Castro, D. (2017), "Trade Liberalization and Gender Wage Gap in Mexico", Modern Economy, 8, 1167-1185. https://doi.org/10.4236/me.2017.810081

Ruiz, P., y Ordaz, L. (2011), "Evolución reciente del empleo y el desempleo en México", Economía Unam, 8(23), 91-105.

Salgado, M. y Miranda, S. (2007), "Mercado de trabajo y profesionistas en el Estado de México", Quivera, 9, 223-247.

Whitehouse, G. (1992), "Legislation and labour market gender inequality: an analysis of OECD countries", Work, employment and society, 6(1), 65-86. 